\title{
Pain among nursing home patients in the Netherlands: prevalence, course, clinical correlates, recognition and analgesic treatment - an observational cohort study
}

\author{
Martin Smalbrugge*1,2, Lineke K Jongenelis ${ }^{1,2}$, Anne Margriet Pot ${ }^{1,2,3}$, \\ Aartjan TF Beekman ${ }^{2,4}$ and Jan A Eefsting1,2
}

Address: ${ }^{1}$ Department of Nursing Home Medicine, VU University Medical Center, Amsterdam, The Netherlands, ${ }^{2}$ Institute of Extramural Medicine (EMGO), VU University Medical Center, Amsterdam, The Netherlands, ${ }^{3}$ Trimbos-institute, Netherlands Institute of Mental Health and Addiction, Utrecht, The Netherlands and ${ }^{4}$ Department of Psychiatry, VU University Medical Center, Amsterdam, The Netherlands

Email: Martin Smalbrugge* - m.smalbrugge@vumc.nl; Lineke K Jongenelis - k.jongenelis@vumc.nl; Anne Margriet Pot - am.pot@vumc.nl; Aartjan TF Beekman - aartjanb@ggzba.nl; Jan A Eefsting - ja.eefsting@vumc.nl

* Corresponding author

Published: 14 February 2007

BMC Geriatrics 2007, 7:3 doi:10.1 186/147|-2318-7-3

This article is available from: http://www.biomedcentral.com/I47/-23/8/7/3

(C) 2007 Smalbrugge et al; licensee BioMed Central Ltd.

This is an Open Access article distributed under the terms of the Creative Commons Attribution License (http://creativecommons.org/licenses/by/2.0), which permits unrestricted use, distribution, and reproduction in any medium, provided the original work is properly cited.
Received: 26 May 2006

Accepted: 14 February 2007

\begin{abstract}
Background: Pain is highly prevalent in nursing homes $(\mathrm{NH})$ in several countries. Data about pain in Dutch NH's, where medical care is delivered by specifically trained $\mathrm{NH}$-physicians, are not available. The aim of the present study is to determine prevalence, course, correlates, recognition and treatment of pain among Dutch NH-patients and to make a comparison with international data.
\end{abstract}

Methods: The study-population consisted of 350 elderly NH-patients from 14 Dutch NH's. Pain (pain-subscale Nottingham Health Profile) and clinical characteristics (gender, age, cognition, depression, anxiety, sleeping problems, morbidity and functional status) were measured at baseline and at six months.

Association of pain (baseline and six months) with clinical characteristics was assessed with chisquare and multiple logistic regression analyses.

Results: Pain-prevalence was $68.0 \%$ (40.5\% mild pain symptoms, $27.5 \%$ serious pain symptoms). $80 \%$ of the patients with pain at baseline still experienced pain at six months. Serious pain at baseline was significantly associated with depression (OR: 2.56; 95\% CI: 1.34-4.89) and anxiety (OR $2.47 ; 95 \% \mathrm{Cl}$ : 1.22-4.99). Serious pain at six months was associated with pain at baseline (OR I8.55; 95\% Cl: 5.19-66.3I) and depression at baseline (OR: 2.63; 95\% Cl: I.10-6.29). Recognition of pain by $\mathrm{NH}$-physicians varied (35\% to $69.7 \%$ ) depending on measurement instrument and severity of pain. Analgesics were received by $64.5 \%$ (paracetamol (acetaminophen), NSAIDs, opioids). Paracetamol (acetaminophen) and opioids frequently were prescribed below daily defined doses.

Conclusion: Pain occurred frequently also among Dutch $\mathrm{NH}$-patients and was associated with depression and anxiety. Recognition and treatment by $\mathrm{NH}$-physicians proved sub-optimal. Future studies should focus on interventions to improve recognition and treatment of pain. 


\section{Background}

One of the main goals of nursing home care is preservation of the best possible quality of life. A very important aspect of quality of life is being free of pain. Prompt recognition and adequate treatment is therefore requested when nursing home patients are suffering from pain.

Previous studies in several countries showed that pain is a common problem in the long-term care setting [1-3]. Prevalence rates ranged from $27 \%$ to $83 \%$, with the highest rates in studies that used patients self-report. One longitudinal study furthermore indicated that pain is chronic in many patients [4]. Factors found to be associated with pain included depression, anxiety, impaired sleep, comorbidity, reduced mobility and decreased involvement in recreational activities [5-7]. Recognition of pain by nursing home staff is poor and frequently no treatment is given [3].

For the Netherlands, in which nursing home physicians are employed by nursing homes for medical care and in which nursing home medicine is an independent medical specialism with its own specific training programme $[8,9]$, epidemiological data about pain in nursing homes are lacking until now. More knowledge about pain in Dutch nursing homes can contribute to a further improvement of the quality of medical care and the quality of life of its residents.

The aim of the present study was therefore (a) to determine prevalence, course, correlates, recognition and treatment of pain in Dutch nursing home patients and (b) to make a comparison with international data.

\section{Methods \\ Study population}

This study is based on data collected in the Amsterdam Groningen Elderly Depression (AGED) study [10]. Fourteen nursing homes in the North West of the Netherlands were selected to participate. Nursing homes for specific disease categories were excluded as were small nursing homes ( $<60$ beds). No large reorganization or rebuilding activities were allowed because of possible influence on the mood of the respondents. To be eligible, subjects had to be aged 55 years and over, speakers of Dutch and able to communicate sufficiently, without serious hearing problems or severe cognitive impairment (Mini-Mental State Examination >= 15) [11].

Patients with at baseline an expected stay of less than 6 months were excluded. All eligible patients were informed verbally and in writing. Written informed consent was obtained from all respondents prior to inclusion. The study received approval from the Medical Ethics Committee of the VU University Medical Center.
Between November 1999 and May 2001, data were collected. All measurements were administered twice in a face to face interview: at baseline and six months later. Sampling procedures are described in detail elsewhere [10].

From the source population (696 nursing home patients who met inclusion criteria) eventually an active sample of 350 patients remained who participated in the baseline data-collection. 58 patients $(8.3 \%)$ died before the interview could be started and 46 patients $(6.6 \%)$ could not be interviewed because they were suffering from acute illness, terminal illness or coma. 235 patients (33.8\%) refused to participate in this study and 7 patients $(1.0 \%)$ were not included for other reasons.

In the second wave at six months $229(65.4 \%$ of the original 350) patients participated; 43 (12.3\%) patients died; $16(4.6 \%)$ patients had severe cognitive impairment; 9 (2.6\%) patients were unable to communicate; 15 (4.3\%) patients were hospitalised or moved; 35 (10\%) patients refused and $3(0.9 \%)$ patients were lost to follow-up for other reasons.

\section{Measurement instruments \\ Measurement of pain}

Perceived pain was measured with the pain subscale of the Dutch version of the Nottingham Health Profile, which measures pain by selfreport [12]. The pain subscale of the Nottingham Health Profile contains 8 items with a yes-no format and a score ranging from 0 to $8(0=$ no pain symptoms). Cronbach's alpha was 0.70 in the present study. The internal consistency of the reliability of the pain scale in previous studies [12-14] proved also to be satisfying (Cronbach's alpha:0.70-0.85) as was the test-retest reliability (Spearman's r: 0.84).

The items of the pain subscale concern pain intensity as well as situations in which pain occurs (i.e. 'suffering unbearable pain' or ' pain when walking': see table 1).

Pain was therefore used in analyses as an ordinal variable and not as a continuous variable. Painstatus was scored as $0=$ no pain, as $1=$ mild pain symptoms or as $2=$ serious pain symptoms. Patients with serious pain symptoms had to report 'unbearable pain' or 'constant pain'. Patients with mild pain symptoms reported positive on other items but had no 'unbearable pain' and no 'constant pain'.

Recognition of pain was measured by asking the attending nursing home physician at baseline if the patient experienced pain in the past two weeks. Medical care in Dutch nursing homes is delivered on a daily basis by specially trained and registered nursing home physicians. Recogni- 
Table I: Pain symptoms measured by the pain section of the Nottingham Health Profile (NHP) in a sample $(n=350)^{a}$ of Dutch nursing home patients at baseline and after six months.

\begin{tabular}{|c|c|c|}
\hline & baseline $n(\%)$ & six months $n(\%)$ \\
\hline \multirow[t]{2}{*}{ Nightly pain } & $75(34.7 \%)$ & $68(31.5 \%)$ \\
\hline & & $(38(50.7 \%) \text { persistent })^{b}$ \\
\hline \multirow[t]{2}{*}{ Unbearable pain } & $29(13.4 \%)$ & $34(15.7 \%)$ \\
\hline & & (17 (58.6\%) persistent) \\
\hline \multirow{2}{*}{ Pain when changing position } & $88(40.7 \%)$ & $83(38.4 \%)$ \\
\hline & & (57 (64.8\%) persistent) \\
\hline \multirow[t]{2}{*}{ Pain when walking } & $45(20.8 \%)$ & 44 (20.4\%) \\
\hline & & (23 (5I.1\%) persistent) \\
\hline \multirow{2}{*}{ Pain when standing } & $49(22.7 \%)$ & $4 \mid(19.0 \%)$ \\
\hline & & (I7 (34.7\%) persistent) \\
\hline \multirow[t]{2}{*}{ Constant pain } & $50(23.1 \%)$ & $47(21.8 \%)$ \\
\hline & & (33 (66.0\%) persistent) \\
\hline \multirow[t]{2}{*}{ Pain when stair climbing } & 7 (3.2\%) & $3(1.4 \%)$ \\
\hline & & (I (14.3\%) persistent) \\
\hline \multirow{2}{*}{ Pain when sitting } & $89(4 I .2 \%)$ & $66(30.6 \%)$ \\
\hline & & (44 (49.4\%) persistent) \\
\hline
\end{tabular}

a Data pain section NHP at baseline and after six months available for 216 patients.

b The number (\%) of patients in whom after six months the symptom still is present

tion was also measured by recording if patients were treated with analgesics. Analgesic drug use, including the prescribed daily dose/defined daily dose ratio (PDD/ DDD-ratio), was assessed by chart review and was classified according to the Anatomical Therapeutic Chemical (ATC) classification system [15]. The PDD/DDD-ratio is used as an indication of the adequacy of dosing. Three main groups of analgesics were distinguished: paracetamol (acetaminophen), non-steroidal anti-inflammatory drugs (NSAIDs) and opioids.

Prescription of antidepressants and of anxiolytics/hypnosedatives (mainly bezodiazepines) was also registrated.

\section{Measurement of correlates}

Demographic characteristics like age and gender were gathered by chart review. Cognitive functioning was assessed with the Mini-Mental State Examination (MMSE) [11]. Sum scores were dichotomized: a score between 15 and 23 referred to the presence of cognitive impairment. A cut-of score of 15 was chosen as exclusion criterion: required for a reliable use of the Geriatric Depression scale.

Depressive symptoms were measured with the Geriatric Depression Scale [16]. A score of $>=11$ was considered to be indicative for the presence of clinically relevant depressive symptoms.

Anxiety was measured with the Schedules for Clinical Assessment in Neuropsychiatry [17]. Anxiety symptoms were defined as presence of phobic complaints or presence of feelings of anxiety or panic in the last four weeks.
Sleep was also measured with the SCAN. Presence of impaired sleep was defined as having troubles falling asleep or being awake in the night (both for at least one hour, three or more times a week, during at least one month) or waking up early (two hours earlier than normally, three or more times a week, during at least one month).

Information about the presence of physical illnesses was obtained from the attending physician using a questionnaire containing thirteen main groups of somatic diseases. The total number of physical illnesses was dichotomized on the median.

Data on functional limitations were supplied by care personnel involved in direct daily care, using the Groningen Activity Restriction Scale (GARS): 11 items concerning Activities of Daily Living [18]. Sum scores (11-44) were dichotomized on the median. Higher scores mean more disability.

\section{Statistical analyses}

Analysis of attrition was done by comparing baseline characteristics (chi-square analyses) of patients who could be interviewed at baseline and at six months with baseline characteristics of patients who could only be interviewed at baseline.

Prevalence of pain was calculated at baseline and at six months. The relations between pain at baseline and demographic and clinical characteristics were evaluated by calculating crude odds ratios (OR) and corresponding 95\% confidence intervals (CI). As a next step multiple 
logistic regression was used to calculate adjusted odds ratios. Only variables with a statistically significant $(\mathrm{p}<$ 0.05 ) crude odds ratio were entered in the multiple logistic regression model.

To identify baseline characteristics that were associated with presence of pain at six months the same analyses were done with pain at six months as dependent variable. Presence of pain at baseline was entered in these analyses also as an independent variable.

The course of pain was described in two ways. Firstly, at NHP symptom level. For all eight NPH items the course of the symptom over six months was assessed (see table 1). Secondly, the course was described for the constructed ordinal pain variable (no pain, mild pain symptoms, serious pain symptoms).

Prevalence of analgesic use and prescription of antidepressants and of anxiolytics/hypnosedatives were calculated at baseline and at six months and differences in use in patients with and without symptoms of pain were assessed.

\section{Results \\ Sample and attrition}

Demographic and clinical characteristics are shown in table 2. About two thirds of the sample were women, their mean age was 79.3 (SD 8.3) years. All patients had moderate to severe functional impairments.

Analysis of attrition showed no statistically significant differences in baseline characteristics between patients who participated in data-collection at baseline and at six months, and patients who only participated at baseline.

\section{Prevalence, risk-indicators and course}

The prevalence of pain was $68.0 \%$ at baseline: $40.5 \%$ ( $\mathrm{n}=$ 138 ) had mild pain symptoms and $27.5 \%(\mathrm{n}=94)$ had serious pain symptoms.

Table 3 shows that presence of serious pain symptoms at baseline was statistically significant associated in multiple logistic regression analysis with presence of depressive symptoms and presence of anxiety symptoms. This association was not found for presence of mild pain symptoms.

Presence of serious pain symptoms at six months was in multiple logistic regression analysis statistically significant associated with presence of pain (OR 18.55; 95\% CI

Table 2: Demographic and clinical characteristics of a sample of nursing homepatients in the Netherlands $(n=350)$.

\begin{tabular}{|c|c|c|}
\hline Characteristic & $\mathrm{N}$ & $\%$ \\
\hline \multicolumn{3}{|c|}{ Age (mean 79.3; SD 8.3; range:55-99) } \\
\hline $55-79$ & 169 & 48.3 \\
\hline $80-99$ & 181 & 51.7 \\
\hline \multicolumn{3}{|l|}{ Sex } \\
\hline Male & 109 & 31.1 \\
\hline Female & 241 & 68.9 \\
\hline \multicolumn{3}{|l|}{ Length of stay } \\
\hline$>$ I year & 209 & 59.7 \\
\hline$<$ I year & $14 \mid$ & 40.3 \\
\hline \multicolumn{3}{|c|}{ Cognitive functioning (MMSE) (mean 22.0; SD 3.8; range 15-30) } \\
\hline $15-23$ & 221 & 63.1 \\
\hline $24-30$ & 129 & 36.9 \\
\hline \multicolumn{3}{|c|}{ Depressive symptoms (GDS >= II) } \\
\hline Present & 155 & 44.3 \\
\hline not present & 195 & 55.7 \\
\hline \multicolumn{3}{|c|}{ Anxiety symptoms $(n=333)$} \\
\hline Present & 99 & 29.7 \\
\hline not present & 234 & 70.3 \\
\hline \multicolumn{3}{|c|}{ Impaired sleep $(n=326)$} \\
\hline Present & 89 & 27.3 \\
\hline not present & 237 & 72.7 \\
\hline \multicolumn{3}{|c|}{ Number of physical illnesses $(n=300)$ (mean 3.7; SD I.6; range I-9) } \\
\hline$<=3$ & 145 & 48.3 \\
\hline$>3$ & 155 & 51.7 \\
\hline \multicolumn{3}{|c|}{ Functional impairments $(n=340)$} \\
\hline Severe & 172 & 50.6 \\
\hline Moderate & 168 & 49.4 \\
\hline
\end{tabular}


Table 3: Clinical characteristics associated with presence of pain at baseline in a sample $(n=350)^{a}$ of Dutch nursing home patients.

\begin{tabular}{|c|c|c|c|c|}
\hline \multirow[t]{2}{*}{ Characteristic } & \multicolumn{2}{|c|}{ Mild pain symptoms $\mathrm{n}=138$} & \multicolumn{2}{|c|}{ Serious pain symptoms $n=94$} \\
\hline & Crude OR $(95 \% \mathrm{Cl})^{\mathrm{b}}$ & Adjusted OR $(95 \% \mathrm{Cl})^{\mathrm{c}}$ & Crude OR $(95 \% \mathrm{Cl})^{\mathrm{b}}$ & Adjusted OR $(95 \% \mathrm{Cl})^{\mathrm{c}}$ \\
\hline Age $(>=80 /<80)$ & $0.83(0.50-1.37)$ & & $0.61(0.35-1.07)$ & \\
\hline Sexe (female/male) & $1.11(0.65-1.88)$ & & $1.48(0.8 \mathrm{I}-2.70)$ & \\
\hline MMSE-score $(>23 /<=23)$ & $1.13(0.67-1.91)$ & & $1.33(0.75-2.34)$ & \\
\hline Depressive symptoms (yes/no) & $1.67(0.98-2.84)$ & & $3.55(1.98-6.35)$ & $2.56(1.34-4.89)$ \\
\hline Anxiety symptoms (yes/no) & $1.82(0.97-3.38)$ & & 3.77 (1.98-7.17) & $2.47(1.22-4.99)$ \\
\hline Sleeping problems (yes/no) & $1.76(0.94-3.29)$ & & $2.55(1.32-4.90)$ & $1.87(0.92-3.79)$ \\
\hline Number of physical illnesses $(>3 /<=3)$ & $1.23(0.72-2.11)$ & & $1.66(0.91-3.03)$ & \\
\hline Functional impairments (large/moderate) & $0.95(0.58-1.58)$ & & $1.34(0.77-2.34)$ & \\
\hline
\end{tabular}

a Complete data of all variables were available for 293 patients

b Crude odds ratio (OR) and $95 \%$ confidence intervals $(95 \% \mathrm{Cl})$. Controlgroup $(\mathrm{n}=109)$ : patients without pain.

c Adjusted odds ratio derived from a multiple logistic regression model. As independent variables were entered variables with a statistically significant crude OR. Controlgroup $(n=109)$ : patients without pain.

d Statistically significant OR $(p<0.05)$ in bold characters.

5.19-66.31) and depressive symptoms (OR 2.63; 95\% CI 1.10-6.29) at baseline. Presence of mild pain symptoms at six months was only statistically significant associated with presence of pain at baseline (OR 3.83; 95\% CI 1.94$7.55)$.

Data about the course of pain over six months were available for 216 patients. Especially 'unbearable pain' (58.6\%) and 'constant pain' (66.0\%) are persistent over time (table 1$)$. Nearly $80 \%(121 / 153)$ of the patients with pain at baseline still reported pain after six months (table 4).

\section{Recognition and treatment}

Presence of mild pain symptoms was recognized in 34.4\% and presence of serious pain symptoms was recognized in $38.2 \%$ of the patients, when measured by interviewing the attending physician.

Pain-recognition was also measured by assessing prescription of analgesics (see table 5). Pain was then recognized in $61.2 \%$ of the patients with mild pain symptoms and in $69.7 \%$ of the patients with serious pain symptoms.
Table 5 shows that treatment with analgesics occurred frequently in the present population: $54.5 \%(158 / 290)$ had analgesics prescribed at baseline, prescription as needed included (8.6\%). Analgesic prescription rate was the highest among patients who reported pain $(64.5 \%$, pnr included). Paracetamol (acetaminophen) was the most frequently prescribed analgesic, followed by NSAIDs and opioids.

The observed differences in analgesic therapy (monotherapy, combination therapy, prescription as needed, no therapy) between patients with pain (mild pain symptoms and serious pain symptoms) and without pain were statistically significant (Pearson chi-square 34.26; df 6; $\mathrm{p}$ $<0.0001$ ). Further analyses showed no significant difference in analgesic therapy between patients with mild pain symptoms and serious pain symptoms (Pearson chisquare $3.44 ; \mathrm{df} 3 ; \mathrm{p}=0.30$ ).

The majority of analgesic users at baseline still reported pain. Only $31(19.6 \%)$ of them were free of pain, 74 $(46.8 \%)$ still experienced mild pain symptoms and 53 (33.5\%) still experienced serious pain symptoms.

Table 4: Course of pain symptoms in a sample $(n=350)^{a}$ of Dutch nursing home patients over six months.

\begin{tabular}{lllll}
\hline & \multicolumn{3}{c}{ Follow-up (6 months) } \\
& No pain & Mild pain symptoms & Serious pain symptoms & Total \\
\hline Baseline & & & & \\
No pain & 39 & 21 & 3 & 63 \\
Mild pain symptoms & 27 & 52 & 16 & $\mathbf{9 5}$ \\
Serious pain symptoms & 5 & 14 & 39 & $\mathbf{5 8}$ \\
Total & $\mathbf{7 1}$ & $\mathbf{8 7}$ & $\mathbf{5 8}$ & $\mathbf{2 1 6}$ \\
\hline
\end{tabular}

a Data about pain symptoms at baseline and after six months available for 216 patients. 
Table 5: Pain and prescription of analgesics, antidepressiva and anxiolytica/hypnosedativa at baseline in a sample $(n=350)^{a}$ of Dutch nursing home patients.

\begin{tabular}{|c|c|c|c|}
\hline & No pain $n=93$ & Mild pain symptoms $n=121$ & Serious pain symptoms $n=76$ \\
\hline Analgesic monotherapy & $25(26.9 \%)$ & $53(43.8 \%)$ & $33(43.4 \%)$ \\
\hline Paracetamolb & $14(15.1 \%)$ & 31 (25.6\%) & $13(17.1 \%)$ \\
\hline NSAIDs & $7(7.5 \%)$ & $20(16.5 \%)$ & II (14.5\%) \\
\hline Opioids & $4(4.3 \%)$ & $2(1.7 \%)$ & $8(10.5 \%)$ \\
\hline Other analgesics & $0(0.0 \%)$ & $0(0.0 \%)$ & I (I.3\%) \\
\hline Analgesic combination therapy & $0(0.0 \%)$ & $10(12.1 \%)$ & $12(15.8 \%)$ \\
\hline Paracetamol and NSAIDs & $0(0.0 \%)$ & $5(4.1 \%)$ & $4(5.3 \%)$ \\
\hline Paracetamol and opioids & $0(0.0 \%)$ & $5(4.1 \%)$ & $5(6.6 \%)$ \\
\hline $\begin{array}{l}\text { Paracetamol, NSAIDs and } \\
\text { opioids }\end{array}$ & $0(0.0 \%)$ & $0(0.0 \%)$ & $2(2.6 \%)$ \\
\hline Opioids and opioids & $0(0.0 \%)$ & $0(0.0 \%)$ & $\mathrm{I}(1.3 \%)$ \\
\hline Analgesic prnc & $6(6.5 \%)$ & $11(9.1 \%)$ & $8(10.5 \%)$ \\
\hline No analgesic & $62(66.7 \%)$ & 47 (38.8\%) & $23(30.3 \%)$ \\
\hline Antidepressiva & $20(21.5 \%)$ & $30(24.8 \%)$ & $26(34.2 \%)$ \\
\hline Anxiolyticalhypnosedativa & $34(36.6 \%)$ & $66(54.5 \%)$ & 37 (48.7\%) \\
\hline
\end{tabular}

a Complete pain data and prescription data at baseline were available of 290 patients.

b Paracetamol $=$ acetaminophen

c Prescription as needed: did not occur with standard prescription of analgesics in this sample.

Data of analgesic use at six months depicted similar results (data not shown).

Considering the adequacy of dosing, opioid-presciptions had in $12.5 \%$ a PDD/DDD-ratio of 1 and in $69.2 \%$ a PDD/DDD-ratio lower than 2/3. Paracetamol (acetaminophen) prescriptions showed in $15.5 \%$ a PDD/DDD ratio of 1 and in $30.8 \%$ a PDD/DDD-ratio lower than 2/ 3. NSAIDs were prescribed in $84.0 \%$ with a PDD/DDDratio of $>=1$ and in $16.0 \%$ with a PDD/DDD-ratio below 1 .

Combinations of analgesics were prescribed to 12.1$15.8 \%$ of the patients with pain at baseline.

There was no significant difference in antidepressants prescription (Pearson chi-square 2.42; df 2; $\mathrm{p}=0.30$ ) between patients with pain (mild pain symptoms and serious pain symptoms) and without pain, but patients with pain (mild pain symptoms and serious pain symptoms) used significantly more frequently anxiolytics/hypnosedatives than patients without pain (Pearson chisquare 6.39; df 2; $\mathrm{p}=0.04$ ). Further analyses showed no significant difference in prescription of anxiolytics/hypnosedatives between patients with mild pain symptoms and patients with serious pain symptoms (Pearson chisquare $0.64 ; \mathrm{df} 1 ; \mathrm{p}=0.42$ ).

\section{Discussion}

\section{Prevalence, risk-indicators, course}

The prevalence of self-reported pain was high in this population of nursing home patients: $40.5 \%$ of the patients reported mild pain symptoms and an additional $27.5 \%$ serious pain symptoms at baseline. Only $32.0 \%$ was free of pain. This was in line with previous studies which used self-reported pain as method of pain measurement $[5,19$ 22]. Pain further appeared to be persistent: nearly $80 \%$ of the patients with pain at baseline still reported pain after six months. A rather alarming observation was that 'unbearable pain' and 'constant pain', the most serious NHP-pain items, also tended to be persistent $(58.6 \%$ and $66.0 \%$ ) over a six months period.

Important associated characteristics with serious pain symptoms at baseline were presence of depressive symptoms and presence of anxiety symptoms. Serious pain symptoms at six months were associated with pain at baseline and with presence of depressive symptoms.

The observed association with depressive symptoms and anxiety symptoms was also found in previous investigations [5]. In a longitudinal study the association between pain and depressive symptoms was found to be intimate and reciprocal [23]. As a consequence, when assessing and treating pain, attention should also be paid to diagnosing and treating depressive and anxiety symptoms.

Contrary to previous studies, no association of selfreported pain with cognitive functioning was observed $[20,24]$. This could be caused by the fact that in the present study only patients with a MMSE-score $>=15$ were included, which implies that more severely demented patients were excluded. 


\section{Recognition and treatment}

Recognition of pain measured by interview and recognition of pain measured by prescription of analgesics resulted in different recognition rates: $35-40 \%$ vs. $61.2-$ $69.7 \%$, presumably because they reflect two ways of defining pain recognition. Analgesics prescription as measurement for pain recognition indicates that at some moment (before or after admission to the nursing home) a physician diagnosed pain and prescribed an analgesic.

A positive interview-answer as measurement for pain recognition indicates that the physician recognized that the patient experienced pain at the time of the interview.

Both methods of measuring pain recognition made clear that presence of pain in many patients remained undetected. Previous studies showed similar results, not only for recognition of pain by physicians but also for recognition by nursing staff [25].

False attitudes about pain and age among elderly patients and their caregivers and non-communication about pain between patients and caregivers were held responsible for this underdetection [25].

Treatment with analgesics occurred frequently in the present population: $54.5 \%$. Analgesic prescription rate was the highest among patients who reported pain (64.5\%, pnr included). Paracetamol (acetaminophen) was used the most frequently, followed by NSAIDs and opioids. In spite of use of analgesics many patients still reported pain. Underdosing of analgesics and a restrained prescription of combinations of analgesics and of opioids could be potential causes.

Underdosing, for which a PDD/DDD-ratio below 1 is indicative, was indeed observed, especially for opioids (PDD/DDD-ratio < 2/3: 69.2\%) and to a lesser extent also for paracetamol (acetaminophen) (PDD/DDD-ratio < 2/ 3: 30.8\%). PDD/DDD-ratio for NSAIDs on the other hand was relatively high ( $84 \%$ PDD/DDD-ratio > $=1$ ) in view of the risk of renal failure and hypertension for older patients [26]. A similar pattern of underdosing was found in a pharmaco-epidemiological study in six nursing homes [27].

Combinations of analgesics were prescribed to 12.1$15.8 \%$ of the patients with pain at baseline. Given the fact that these patients still had pain, one would expect a higher rate of combinations of analgesics.

Opioids were prescribed to $11.7 \%$ of the patients with pain at baseline and about half of the opioid-prescriptions were given as monotherapy. This seems not in line with pain-guidelines which advise opioids to be added to
NSAIDs and paracetamol (acetaminophen) as a next step in analgesic treatment [28].

The high prevalence of pain in the present study and the observations made about recognition and treatment of pain suggest that in nursing homes in the Netherlands, pain-management is suboptimal just as was found in studies among nursing home populations in other countries, despite the deliverance of medical care by specifically trained nursing home physicians.

Assessment of pain by a standardized instrument at regular times, which is uncommon in the Netherlands (use of screening instruments like the Resident Assessment Instrument [29] is not mandatory) and interdisciplinary discussion of the assessment results by nursing staff and attending physician, may help to improve pain-management in nursing home patients [30]. The interdisciplinary discussion also offers a good opportunity for better implementation of recently published pain-guidelines [28].

Future studies should investigate if a standardized pain assessment and an interdisciplinary discussion of the assessment have a positive effect on pain among nursing home patients.

\section{Limitations}

The present study has some limitations, which warrant comment. Firstly, the study-population is a selective one. Serious cognitive impairment (MMSE <15), speech and language problems, severe physical illness and expected discharge within six months were important exclusion criteria.

Secondly, attrition was considerable as could be expected among the frail population of elderly patients residing in nursing homes. Nevertheless, analysis of attrition showed no differences in distribution of baseline-characteristics between patients who remained in the study and patients who dropped out.

Thirdly, pain was measured with the NHP-pain subscale which contains items concerning different aspects of pain (pain-intensity as well as items concerning situations in which pain is present). We therefore constructed an ordinal pain variable, that in our opinion has satisfying clinical face validity by using intensity and long lasting presence of pain for defining more severe pain.

\section{Conclusion}

Pain is a common and usually persistent problem among nursing home patients.

Important associations are observed with depressive and anxiety symptoms. 
Recognition by nursing home physicians in the Netherlands is comparable to recognition in other countries and open for improvement.

Despite a high prescription rate of analgesics, many patients still report pain. This may be caused by underdosing and restrained use of analgesic combination therapy.

To warrant optimal quality of life of nursing home patients improvement of pain recognition and treatment is needed. Introduction of standardized pain assessments at regular times, treatment according to pain guidelines and interdisciplinary discussion of the assessment results and treatment effects, may help to establish this.

\section{Competing interests}

The author(s) declare that they have no competing interests.

\section{Authors' contributions}

All authors contributed to the study conception and design. MS participated in the data analysis and drafting of the manuscript, LJ participated in the data collection, $\mathrm{AP}$ participated in the data analysis, $\mathrm{AB}$ participated in the data analysis, JE participated in the data analysis. All authors critically reviewed the manuscript, read and approved the final manuscript.

\section{Acknowledgements}

This study is based on data, which were collected in the context of the Amsterdam Groningen Elderly Depression (AGED) study, conducted at the Department of Nursing Home Medicine and Psychiatry and the Institute of Extramural Medicine (EMGO), VU University Medical Center in Amsterdam and the Department of Social Psychiatry, University Medical Center in Groningen.

The study was primarily funded by the Dutch Organization of Scientific Research (NWO), Programme chronic disease (940-33-04I). Additional financial support was received from Foundation De Open Ankh and Bovenwegen and Society Het Zonnehuis.

\section{References}

I. Fox PL, Raina P, Jadad AR: Prevalence and treatment of pain in older adults in nursing homes and other long-term care institutions: a systematic review. CMAJ 1999, I60:329-333.

2. Won A, Lapane K, Gambassi G, Bernabei R, Mor V, Lipsitz LA: Correlates and management of nonmalignant pain in the nursing home. SAGE Study Group. Systematic Assessment of Geriatric drug use via Epidemiology. J Am Geriatr Soc 1999, 47:936-942.

3. McClean WJ, Higginbotham NH: Prevalence of pain among nursing home residents in rural New South Wales. Med J Aust 2002, I 77: 17-20.

4. Won AB, Lapane KL, Vallow S, Schein J, Morris JN, Lipsitz LA: Persistent nonmalignant pain and analgesic prescribing patterns in elderly nursing home residents. J Am Geriatr Soc 2004, 52:867-874.

5. Parmelee PA, Katz IR, Lawton MP: The relation of pain to depression among institutionalized aged. J Gerontol I99I, 46:PI5-2I.

6. Ferrell BA, Ferrel BR, Osterweil D: Pain in the nursing home. J Am Geriatr Soc 1990, 38:409-4I4.
7. Basler HD, Hesselbarth S, Kaluza G, Schuler M, Sohn W, Nikolaus T: Comorbidity, multiple medication, and well-being in elderly patients with chronic pain. Schmerz 2003, I 7:252-60.

8. Hoek JF, Ribbe MW, Hertogh CMPM, van der Vleuten CPM: The role of the specialist physician in nursing homes: the Netherlands' experience. Int J Geriatr Psychiatry 2003, I 8:244-249.

9. Ribbe $M W$ : Care for the elderly: the role of the nursing home in the Dutch health care system. Int J Psychogeriatr 1993, 5:213-222.

10. Jongenelis K, Pot AM, Eisses AMH, Beekman ATF, Kluiter H, Ribbe $M W$ : Prevalence and risk indicators of depression in elderly nursing home patients: the AGED Study. J Affect Disord 2004, 83: $135-\mid 42$.

II. Folstein MF, Folstein SE, McHugh PR: Mini-Mental State. A practical method for grading the cognitive state of patients for the clinician. J Psychiatr Res 1975, I 2:189-198.

12. Erdman RAM, Passchier J, Kooijman M, Stronks DL: The Dutch version of the Nottingham Health Profile: investigations of psychometric aspects. Psychological Reports 1993, 72:1027-1035.

13. van Campen C, Kerkstra A: Perceived quality of life of physically frail elderly patients in nursing homes: Construction of a measuring-instrument. Tijdschr Gerontol Geriatr 1998, 29: I I- I8.

14. Holtkamp CCM: Effects of the resident Assessment instrument on quality of care and quality of life in nursing homes. In PhD Thesis Amsterdam, Free University; 2003.

15. World Health Organisation Collaborating Centre for Drug Statistics Methodology: Anatomical Therapeutical Chemical (ATC) classification index including defined daily doses (DDDs) for plain substances. Oslo 1997.

16. Yesavage JA, Brink TL, Rose TL, Lum O, Huang V, Adey M, Leirer V: Development and validation of a geriatric screening scale: $a$ preliminary report. J Psychiatr Res 1983, I 7:37-49.

17. World Health Organization: Schedules for Clinical Assessment in Neuropsychiatry (SCAN). SCAN 2. I: vragenschema's voor de klinische beoordeling in de neuropsychiatrie Edited by: Giel R, Nienhuis FL. Geneve; Dutch Groningen; 1999.

18. Kempen GIJM, Miedema I, Ormel J, Molenaar W: The assessment of disability with the Groningen Activity Restriction Scale. Conceptual framework and psychometric properties. Soc Sci Med 1996, 43:1601-10.

19. Roy R, Thomas M: A survey of chronic pain in an elderly population. Can Fam Physician 1986, 32:513-516.

20. Parmelee PA, Smith B, Katz IR: Pain complaints and cognitive status among elderly institution residents. J Am Geriatr Soc 1993, 41:517-522.

21. Sengstaken EA, King SA: The problems of pain and its detection among geriatric nursing home residents. J Am Geriatr Soc 1993, 41:54I-544.

22. Ferrell BA, Ferrell BR, Rivera L: Pain in cognitively impaired nursing home patients. J Pain Symptom Manage 1995, I 0:591-598.

23. Geerlings SW, Twisk JWR, Beekman ATF, Deeg DJ, van Tilburg W: Longitudinal relationship between pain and depression in older adults: sex, age and disability. Soc Psychiatry Psychiatr Epidemiol 2002, 37:23-30.

24. Scherder E, Bouma A, Slaets J, Ooms M, Ribbe MW, Blok A, Sergeant J: Repeated pain assessment in Alzheimer's Disease. Dement Geriatr Cogn Disord 200I, I 2:400-407.

25. Cowan DT, Fitzpatrick JM, Roberts JD, While AE, Baldwin J: The assessment and management of pain among older people in care homes: current status and future directions. Int J Nurs Stud 2003, 40:291-8.

26. Solomon $\mathrm{DH}$, Gurwitz $\mathrm{JH}$ : Toxicity of non-steroidal anti-inflammatory drugs in the elderly: is advanced age a risk factor? $\mathrm{Am}$ J Med 1997, 102:208-2I5.

27. van Dijk KN, De Vries CS, van den Berg PB, Brouwers JR, de Jong-van den Berg LT: Drug utilization in Dutch nursing homes. Eur J Clin Pharmacol 2000, 55:765-7I.

28. American Geriatrics Society. AGS Panel on Persistent Pain in Older Persons: The management of persistent pain in older persons. J Am Geriatr Soc 2002, 50(Suppl):S205-24.

29. Morris JN, Murphy K, Nonemaker S: Long term care facility Resident Assessment Instrument (RAI) user's manual version 2.0 Baltimore: HFCA; 1995.

30. Weiner DK: Pain in nursing home residents: What does it really mean, and how can we help? J Am Geriatr Soc 2004, 52:1020-1022. 


\section{Pre-publication history}

The pre-publication history for this paper can be accessed here:

http://www.biomedcentral.com/1471-2318/7/3/prepub

Publish with Bio Med Central and every scientist can read your work free of charge

"BioMed Central will be the most significant development for disseminating the results of biomedical research in our lifetime. " Sir Paul Nurse, Cancer Research UK

Your research papers will be:

- available free of charge to the entire biomedical community

- peer reviewed and published immediately upon acceptance

- cited in PubMed and archived on PubMed Central

- yours - you keep the copyright 